Revista de la red interuniversitaria de estudios sobre las literaturas rioplatenses contemporáneas en Francia

21 | 2020

Glosolalias transplatinas: fantasmas, utopías y

ficciones lingüísticas

\title{
El poema en lengua babélica de Bernardo Schiavetta
}

Le poème en langue babélique de Bernardo Schiavetta

Bernardo Schiavetta's Babelic Poem

\section{Didier Coste}

\section{CpenEdition}

\section{Journals}

Electronic version

URL: http://journals.openedition.org/lirico/9693

DOI: $10.4000 /$ lirico.9693

ISSN: 2262-8339

Publisher

Réseau interuniversitaire d'étude des littératures contemporaines du Río de la Plata

\section{Electronic reference}

Didier Coste, «El poema en lengua babélica de Bernardo Schiavetta», Cuadernos LIRICO [En línea], 21 2020, Publicado el 12 julio 2020, consultado el 29 enero 2021. URL: http://journals.openedition.org/ lirico/9693 ; DOl: https://doi.org/10.4000/lirico.9693

This text was automatically generated on 29 January 2021.

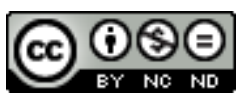

Cuadernos LIRICO está distribuido bajo una Licencia Creative Commons Atribución-NoComercialSinDerivar 4.0 Internacional. 


\title{
El poema en lengua babélica de Bernardo Schiavetta
}

\author{
Le poème en langue babélique de Bernardo Schiavetta \\ Bernardo Schiavetta's Babelic Poem
}

Didier Coste

\section{La lengua babélica}

1 A la vez imaginaria y concreta, la lengua babélica del Almiraphel, poema de Bernardo Schiavetta ${ }^{1}$, no se construye con simples vocablos como unidades de base, sino con frases enteras. Todas ellas son citas de otros autores, rigurosamente referenciadas, extraídas de un stock que incluye un gran número de textos escritos en muy diversos idiomas (más de sesenta), pero también otros tipos de invenciones verbales (entre las cuales varios ejemplos de lenguas imaginarias antiguas y modernas) De manera semejante al collage surrealista o al sampling de ciertos textos electrónicos actuales, el procedimiento compositivo de la lengua babélica es una variante contemporánea de la técnica del antiguo centón o patchwork. ${ }^{2}$ En sus muy diversas versiones, hasta el título del poema babélico ha ido evolucionando, llamándose primero Prosopopeïa o Raphèl y después Almiraphèl remake o simplemente Almiraphèl.

2 El autor ha escrito y reescrito numerosas veces su centón multilingüe, el cual sigue siendo un work in progress hasta la fecha. Durante ese lapso, las primeras redacciones del proyecto babélico así como las sucesivas variantes de la obra propiamente dicha han sido publicadas en una docena de versiones diferentes. Todos esos textos han aparecido mayoritariamente en versión impresa, principalmente en revistas literarias o académicas, pero también en volúmenes colectivos. ${ }^{3}$

En el centón multilingüe, cada frase tiene sentido en su o sus idiomas de origen. Tener sentido es una característica definitoria de las lenguas propiamente dichas, ya sean naturales o artificiales, vivas o muertas. No obstante, tal no es siempre el caso de ciertas invenciones verbales presentes en el centón, las cuales pueden no tener sentido, como 
las glosolalias místicas o los abracadabras mágicos o como algunas célebres seudolenguas del teatro cómico: el falso persa de Aristófanes, el falso cartaginés de Plauto, la falsa lingua franca de Shakespeare o el falso latín de Molière (Schiavetta 2016: 272-274). Abundan también diversas onomatopeyas y transcripciones de sonidos inarticulados.

El cómputo global de las citas que componen las diversas versiones del poema babélico supera ampliamente el centenar, pero lo sorprendente es que alrededor de ochenta fueron utilizadas desde el principio y (aunque hayan variado a menudo de posición) han sido conservadas por el autor en las sucesivas reescrituras del poema.

Schiavetta, que ha residido durante más de cuarenta años en Francia, siempre ha acompañado cada una de las sucesivas redacciones de su poema babélico con una nueva traducción a una lengua natural, mayoritariamente al francés antes de pasar al castellano, lo cual es por cierto indispensable a la comprensión de un texto que su mismo autor califica de monstruoso.

El poema es un monstruo principalmente porque las líneas que lo componen son heteróclitas: a veces fragmentos de prosa, otras veces extractos de canciones (letras con música) y bastante a menudo versos, pero versos pertenecientes a sistemas prosódicos muy distintos (cuantitativos, tónicos, silábicos, etc.). Técnicamente hablando, no se trata de un poema en verso libre, sino de una mezcla radical de prosa y verso. El Almiraphel es por lo tanto un ejemplo extremo de prosimetrum, una mixtura de prosa y verso que corresponde estilísticamente a la estética mordaz de la sátira menipea. Hay alternancias entre refranes populares y máximas filosóficas, entre puerilidades y versos trágicos o épicos, en suma, incongruencias que bajan y alzan el tono de un discurso que oscila irónicamente de lo ridículo a lo sublime. Destacaremos particularmente el Supercalifragilisticexpialidocious de Mary Poppins o el "lenguaje marciano" de la médium suiza Hélène Smith. Ambos ejemplos provienen del Almiraphel remake (Schiavetta 2006b). El poema fue escrito directamente en "lengua babélica". El original ha sido, desde el principio, un patchwork políglota. Por esa razón es posible afirmar que la lengua babélica del Almiraphel es verdaderamente una lengua imaginaria.

\section{El aullido de Nemrod}

7 En el origen del poema hay un verso voluntariamente incomprensible del Canto XXXI del Infierno, de la Divina Comedia de Dante, que sirve de epígrafe a todas las versiones del poema babélico:

Raphél maý améch zabí almi

Así empezó a gritar la fiera boca

Que no sabría hablar más dulcemente.

Y Virgilio le dijo: ¡Alma insensata!

Y a mí después: A sí mismo se acusa,

Éste es Nemrod por cuya fechoría

Ya no usa el mundo un único lenguaje.

Dejémoslo, no hablemos más en vano

Pues no puede entender ninguna lengua

Ni nadie comprender lo que nos dice.

(Dante, 1989: 260. Traducción de Bernardo Schiavetta)

Raphél maý améch zabí almí $i^{4}$ tal es el grito que escapa de la boca de Nemrod, otrora rey de Babel, un gigante que habla en un idioma maldito, que nadie podrá nunca comprender. Dios lo ha condenado a una incomunicación eterna por haber sido 
responsable de la construcción de la Torre de Babel y de la confusión de las lenguas. El título "Almi-raphel" resulta del acoplamiento de la última y de la primera de las cinco seudo palabras inventadas por Dante.

Sin ser una lengua artificial propiamente dicha (ya que no posee hasta la fecha ninguna gramática explícita), la lengua del poema babélico es una lengua imaginaria, más exactamente, como se verá en nuestras conclusiones, una lengua ficticia, intrínsecamente ligada a las aporías y paradojas de la unidad radicalmente híbrida de su complejo procedimiento de composición.

\section{El Almiraphel como procedural poetry}

Schiavetta se inscribe en una importante tendencia postmoderna, que Marjorie Perloff denomina procedural poetry; tales obras utilizan procedimientos de composición poética cuya función es, intrínsecamente, más generativa que expresiva (Perloff 1991: 139). Tales procedimientos son creaciones conceptuales, concebidas en una etapa previa a la escritura poética propiamente dicha, y por esa razón muy a menudo contribuyen a generar no sólo la organización sino la temática misma de los textos resultantes de su empleo.

11 En los trabajos académicos en castellano que han tratado preferentemente de las reglas textuales inventadas o reinventadas en Francia por el grupo Oulipo (creado en 1960 por Raymond Queneau y François Le Lionnais) esos procedimientos suelen ser denominados “constricciones" (Bénabou 1987 : 7-12). Constricción es una traducción aproximativa del termino francés "contrainte". Este último designa tanto las prescripciones como las proscripciones que hay que tener en cuenta para llevar a cabo un proyecto.

12 Según Schiavetta y Baetens (2004 : 344-347), tales creaciones formales conceptuales pueden definirse como reglas textuales no canónicas. Se trata pues de escribir respetando programas cuyas prescripciones o proscripciones pueden llegar hasta a modificar, en ciertos casos extremos, las reglas pragmáticas de la comunicación o las normas lingüísticas propiamente dichas (escribir toda una novela, como La Disparition de Georges Perec, sin la vocal más frecuente en la lengua francesa); más frecuentemente, se trata de invenciones que enriquecen o que modifican las convenciones de los géneros literarios. Gran parte de las publicaciones en verso de Schiavetta, y principalmente su obra más conocida, Fórmulas para Cratilo (1990), Premio Loewe, pertenecen muy claramente a ese tipo de escritura.

En el prólogo al Texto de Penélope, que reúne algunas entrevistas que le hice a Schiavetta, se puede leer:

Con mis características propias, me inscribo en una tendencia específica de la modernidad, minoritaria por cierto, pero que no merece ser ignorada. Tal fue la línea hiperconstructiva y antirromántica de la Filosofía de la composición de Edgar Allan Poe, prolongada y desarrollada por el "método del espejismo" de Stéphane Mallarmé. Tal fue también, de manera muy similar, en prosa, la línea que surge de los "procedimientos" de Raymond Roussel, pasa por la "mise en abyme" de André Gide y desemboca en los dispositivos textuales autorepresentativos del Nouveau Roman de Jean Ricardou. Tal es, en el tiempo presente, la tradición de una producción literaria à contraintes que practican desde hace medio siglo los miembros del grupo Oulipo y diversos autores a nivel internacional (Coste y Schiavetta 2012: 7-8). 
Como lo recordamos más arriba, Marjorie Perloff destacaba la función más generativa que expresiva de los procedimientos compositivos de la procedural poetry. Schiavetta es un escritor que está radicalmente contra la expresión personal del autor, un escritor que dice haber decidido:

... evitar a toda costa que mi yo personal fuese el yo lírico de mis poemas. Esa posición neutra corresponde simplemente a la creatividad dramatúrgica, donde la personalidad propia del poeta es nada y nadie: he is nothing in himself dice Borges de Shakespeare, citando a William Hazlitt [...] Como se habrá comprendido después de leer el párrafo anterior, mi decisión de consagrarme a la ascesis de la expresión personal [...] no es ninguna novedad en la historia de la poesía: tiene un nombre técnico y una prestigiosa genealogía literaria. Por supuesto, no estoy confesando que decidí deshacerme definitivamente de mi ego consciente. Eso no sería sano. Ponerlo a un lado es suficiente, y dejarlo allí. Algo en nosotros debe servir de testaferro y de ama de llaves. (Schiavetta, 2018: 9)

La impersonalidad de la escritura poética ha sido un programa explícito de ciertos movimientos y de ciertos autores modernos. En el caso de Schiavetta estamos ante un caso límite. El imperativo de la impersonalidad y la nadería de la personalidad lo lleva a renunciar, no solo a su lengua materna, sino también a toda lengua natural.

\section{Diagramatismos}

El poema babélico es un ejemplo de lo que Schiavetta llama diagramatismo o escritura diagramática $(1991,1992)$. ¿Qué es una escritura diagramática? Tomemos, para definirla, un ejemplo simple, el más elemental de todos: un poema "en bucle" cuyo último verso es idéntico al primero, y que trata del Eterno Retorno de los pitagóricos. No es un poema de Schiavetta, es "La Noche cíclica" de Borges. La forma global del poema, circular, es el diagrama de su tema principal. Dicho de otra manera: el círculo no es en sí mismo ni una silueta ni un diagrama, es una simple figura geométrica. Sin embargo, al ser interpretado imaginariamente como un signo icónico, se carga de un sentido metafórico, su forma se semantiza y se convierte en un diagrama evocador de procesos cíclicos o de objetos circulares.

17 Lo mismo ocurre con las fórmulas geométricas generativas de Fórmulas para Cratilo (1990), donde no fue el sentido lo que determinó la forma de sus textos, sino que ciertas formas geométricas engendraron el sentido de cada poema. Así, los poemas circulares de Fórmulas para Cratilo tratan de la serpiente que se muerde la cola ("Uróboro"), de los engranajes de un mecanismo ("Espejo del reloj"), de la danza mecánica de una bailarina de caja musical (“...música de caja de...”).

Estas diversas fórmulas diagramáticas se inspiran en las estrofas figuradas helenísticas de la Antología Palatina. Para ejemplificarlo bastará pensar otra vez en una figura geométrica simple: dos triángulos rectángulos unidos por una de sus cúspides: esa forma estrófica sugirió al poeta Simias de Rodas el tema de sus "Alas de Eros"; dos milenios más tarde, el poeta metafísico inglés George Herbert la utilizó para escribir sus "Alas de Pascua", etc. Ciertas organizaciones de tipo quiasmático (o "en espejo"), mucho más abstractas que las anteriores, han evocado los temas de la sección "Espejos" de Fórmulas para Cratilo.

Dado que el poema habla babélicamente de Babel, también debemos suponer que el Almiraphèl debe ser el fruto de una escritura diagramática, puesto que su materia 
lingüística mixta está en una evidente relación de similitud con la confusión bíblica de las lenguas. Como se verá más adelante, la composición diagramática del Almiraphel es extremadamente compleja, pero ya podemos afirmar que el multilingüismo es uno de sus diagramas generativos.

\section{El primer antecedente del poema babélico}

Casi veinte años antes de abocarse a su centón multilingüe, Schiavetta ya había utilizado el grito del Nemrod dantesco como tema central de "Prosopopeïa", poema que figura en su primer volumen de poesía, Diálogo (1983: 84-85). Conviene citar ese texto por entero, dado que resulta ser, sin duda alguna, el primer antecedente directo del poema babélico:

RAPHÉL MAÝ AMÉCH ZABÍ ALMÍ

PROSOPOPEÏA

Raphél maý améch zabí almí

Así empezó a gritar la fiera boca Que no sabría hablar más dulcemente.

Y Virgilio le dijo: ¡Alma insensata!

Y a mí después: A sí mismo se acusa,

Este es Nemrod por cuya fechoría Ya no usa el mundo un único lenguaje. Dejémoslo, no hablemos más en vano Pues no puede entender ninguna lengua

Ni nadie comprender lo que nos dice. DANTE, INFIERNO,

no es posible entender esas palabras pues nada significan: las pronuncia Nemrod, que construyó en Babel la Torre y que está condenado en el infierno a no entender jamás ningún lenguaje RAPHÉL MAÝ AMÉCH ZABÍ ALMÍ él no puede entender esas palabras, las suyas propias, las que nadie entiende; negados, sin callar ni ensordecerse, su boca y sus oídos lo transforman en un lugar adonde las palabras RAPHÉL MAÝ AMÉCH ZABÍ ALMÍ se dicen y se escuchan ellas solas como truena en el cielo tormentoso, como en mí desde siempre las palabras alzan y abaten sus confusas torres que pronuncio y escribo y oigo y leo RAPHÉL MAÝ AMÉCH ZABÍ ALMÍ mientras les voy confiando lo más mío para que se respondan a sí mismas, pues era suyo cuanto así les cedo y sé que apenas soy estas palabras que incomprensiblemente están diciendo RAPHÉL MAÝ AMÉCH ZABÍ ALMÍ sin que puedas callar lo que decimos, 


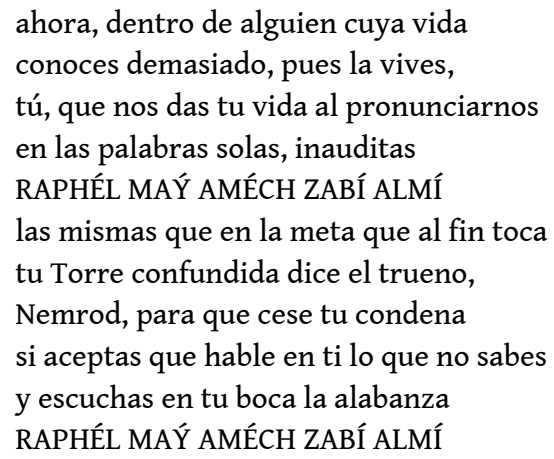

Por otra parte, desde un punto de vista puramente formal, "Prosopopeïa" es evidentemente una glosa en el sentido técnico que toma el término glosa en la prosodia castellana tradicional: un poema que amplifica uno o varios versos de otro poema. Aquí, a la manera de un estribillo, la cita-leitmotiv dantesca se repite regularmente, tal como vuelve, al final de cada estrofa, el verso ajeno "que se alcanza por ventura", en la célebre Glosa a lo divino de San Juan de la Cruz.

\section{Génesis de la glosa en lengua babélica}

Entre 1997 y 2001 Schiavetta compuso una versión de once estrofas del poema en lengua babélica. Varias versiones del poema babélico, por entonces intitulado Raphel, acompañadas de traducciones al francés, al inglés (Monk 2004) o al alemán (PoierBernhard 2004) se sucedieron entre los años 2001 y 2004. Entre los artículos que dieron a conocer el proyecto, el más importante lleva un título meramente descriptivo: Raphel, hiperpoema babélico ilimitado / Raphèl : hyperpoème babélique illimité (Schiavetta 2001b ).

Más de treinta años después de "Prosopopeïa", la estructura fundamental del "hiperpoema" babélico sigue siendo la de la antigua glosa, pero actualmente se ha transformado en una glosa amplificada, amalgamada con las técnicas del centón y del multilingüismo, así como con otro procedimiento híbrido: el prosímetro menipeo.

Como lo subraya Martine Marzloff, una de las características estilísticas de Schiavetta ha sido la de "despertar" antiguos modelos:

Schiavetta utilise les modèles littéraires et artistiques, non pour les détruire, mais pour les développer afin de réveiller les discours convenus et figés. Sa pratique d'écriture est donc liée à une éthique : il ne s'agit pas de nier les modèles, mais de s'en affranchir et de trouver le moyen d'absorber toutes les possibilités de création, sans se prendre trop au sérieux. (2017: 224).

Marzloff dice que la poética de Schiavetta "despierta", antiguos modelos. Tal es claramente el caso (rarísimo) del centón multilingüe. Esta forma fue utilizada en 1609 por Lope de Vega, quien ofrece escrupulosamente a sus lectores las referencias de sus versos-citas (1968: 89-90). Lope y Schiavetta, exhiben sus procedimientos de composición. Fonsalido (2016: 41-54) muestra que los modelos reactivados por Schiavetta se sitúan preferentemente en el Siglo de Oro, como lo hace también Mesa Gacedo (2004-2006: 15-17), acerca de "Cubo de Kepler" un laberinto barroco de Fórmulas para Cratilo (1990: 70-71). 


\section{Desarrollos de la glosa en lengua babélica}

La idea formal y temática de "Prosopopeïa" se reactivó a partir de la práctica de las hiperglosas (Schiavetta 1997: 77-88), que consiste en intercalar versos en el espacio en blanco que separa dos líneas de una poesía; de ese modo, (siempre y cuando se interpolen allí doce versos debidamente rimados) un dístico puede transformarse en un soneto.

En todas las versiones del Almiraphel la primera hiperglosa (la Estrofa Cero) se obtiene intercalando ocho citas sin sentido en el espacio en blanco que separa los versos 67 y 68 del Canto XXXI del Infierno:

Raphél maý améch zabí almi

Así empezó a gritar la fiera boca

Las siguientes son las referencias bibliográficas de las citas asemánticas que Schiavetta introduce en la interlínea dantesca:

"Rarael abra bracha merphergar", es un abracadabra (voces magicae) del Gran Papiro mágico de París (línea 1565); después, "Tsaw latsaw qaw laqaw zir sham", es un tarareo infantil hebreo (Isaías, 28, 10). En tercer lugar viene "Lix tetrax damnameneus aision", un conjuro griego (las Ephesia grammata) conservado en el Lexicon de Hesiquio de Alejandría. En cuarta posición aparecen "jarbhari turphari", dos palabras sánscritas incomprensibles (Rig Veda, X, 106, 6), seguidas de ablanathanalba, un abracadabra greco-egipcio (ver Furtwängler, Adolf, Die antiken Gemmen, 1900, passim). Siguen, por último, las caricaturas teatrales de lenguas extranjeras ya mencionadas: el falso persa de Aristófanes (Acarnienses, 100); el falso fenicio de Plauto (Pœnulus, V, 937); el "Chough's language", o sea la falsa lingua franca de Shakespeare (All's Well That Ends Well, IV, i, 79) y el falso latín de Molière (Le Médecin malgré lui, II, iv).

El resultado es una de las variadas versiones del íncipit del Almiraphel, su "Estrofa cero": la expansión del discurso incomprensible de Nemrod:

Almiraphel, una versión de la estrofa cero

0. [versión en castellano]

¿Raphél maý améch zabíalmí

Rarael abra bracha merphergar

Tsaw latsaw qaw laqaw zir sham

Lix tetrax damnameneus aision

Jarbhari turpharitu ablanathanalba

I artaman exarxan apiaonai

Ythemaneth ihychir saelichot

Oscorbidulchos volivorco

Cabricias arci thuram catalamus?

Así empezó a gritar la fiera boca.

\section{El primer Almiraphel en castellano}

En 2005 aparecen, en la revista argentina Hablar de poesía, seis estrofas del poema babélico, precedidas por un ensayo-ficción de tipo borgesiano, intitulado "Fragmentos de un poema babélico". La publicación de esta versión es absolutamente crucial en la historia de la lengua babélica. 
En primer lugar, porque (a partir de ella y como ella) las redacciones futuras del Almiraphel estarán precedidas por una ficción: el relato imaginario sobre la manera en la que el poema babélico fue escrito. En segundo lugar, 2005 es también una fecha crucial porque la obra babélica recibe en las páginas de "Fragmentos de un poema babélico" el título de Almiraphel, título que llevará el poema en todas las redacciones posteriores, incluida la versión definitiva anunciada oficialmente en "Jugar en serio" (Schiavetta 2018: 7-17).

Reproducimos aquí algunas estrofas. Todas las versiones del poema babélico siguen un orden fijo: comienzan por el epígrafe (siempre el mismo) y acto seguido aparece la "Estrofa Cero" (con variantes según las diversas versiones). Viene después un "Primer Ciclo" de diez estrofas, numeradas secuencialmente: 1,$1 ; 1.2 ; 1,3$, etc. Para facilitar su inteligencia conviene leer en primer lugar la traducción castellana (que da acceso a un sentido plausible aunque no definitivo del texto), luego el texto original en lengua babélica (opaco para el común de los mortales), y finalmente (tarea que será interesante para los lectores borgeanos, tediosa para otros), las notas eruditas a cada una de las líneas del centón.

\title{
1.1
}

\author{
¿Raphèl maý amèch zabí almí? \\ Nemrod, en plena tempestad \\ nutre en su pecho la raíz del trueno \\ y toda la discordia de Babel \\ habla por su boca. \\ ¿Es tan sólo un aullido, es un lenguaje? \\ ¿Cómo podrías traducirlo? \\ ¿Fümms bö wö tää zää Uu pögiff? \\ ¿O bien, acaso, jarbhari turphari \\ raraêl abra bracha merphergar?
}

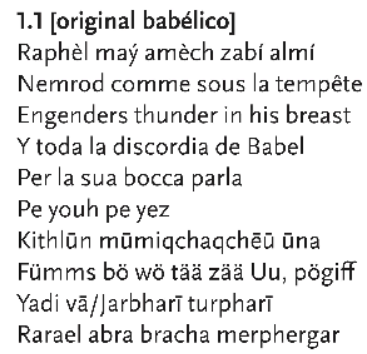

Pseudo-lengua, Dante Alig HIERI, Inferno. Francés, Victor Huco, Nemrod. Inglés, William Shakes Peare, King Henry IV. Español, Juan Luis Borges, Una brújula. Italiano, Micuel Ángel, Rime. Bretón, Pierre-Jakez HÉLIAS, Ar Hambrer. Inuit, Francis BARNUM, Inuit Language. Fonetismos, Kurt SCHWITTERS, Ursonate. Sánscrito, Rig Veda, X, Himnos 129 y 106. Voces magicae, Gran papiro mágico de París. 
1.9

- ¿Raphèl maýamèch zabi almí?

¡Sí y no, no $\gamma$ sí! (es el Habla quien habla)

porque Yo soy la casta prostituta

lo que digo se niega a quien lo escucha.

El universo está hecho de palabras

Yo misma soy palabra entre palabras,

juntas charlamos de todo $y$ de nada

mientras vamos cantando una canción cualquiera:

¡Yo soy Tú! ¡Tú eres Yo! ¡Yo soy Él! ¡Él es Yo!

así comenzó a gritar la fiera boca...

\author{
1.9 [original babélico] \\ Raphèl maý amèch zabí almi \\ Pallaksch pallaksch/Die Sprache spricht \\ Anok gar te xêytera ayô thaê \\ Ėdè ò gbòhùn eleyo \\ Jagat tesusun dari kata \\ $I$ myself am a word with them \\ Wij praten over zoveel dingen \\ Sebarang nyanyi kita nyanyika \\ Neoneun na naneun neo/Aham sah so'ham \\ Cominciò a gridar la fiera bocca
}

Pseudo-lengua, Dante ALICHIERI, inferno. Esquizofasia, F. HölderLIN/Alemán, M. HEIDEGGER. Copto, El Trueno la Mente perfecto.

Yoruba, Olátúndé O OLATÚNJI, adínaton tradicional. Indonesio, Subagio Sastrowardojo, Kata. Inglés, Walt WHITMAN, A Song of the rolling Earth. Flamenco, Hans MELEN, Sonnet aan mijn vrouw. Malayo, pántum tradicional anónimo. Coreano/Sánscrito, palíndromos silábicos. Italiano, Dante Alighierı, inferno.

\subsection{0}

... comenzó a gritar la fiera boca del pecador cuyo nombre es Nemrod. Interrogando a las almas del Hades en su lengua inaudita que nadie sabrá nunca descifrar, Nemrod, el héroe más antiguo, habla consigo a solas.

Confusas/palabras/pronuncia/ Inconcluso/es/poema/aún/acaso/ Raphèl maý amèch zabí almí...

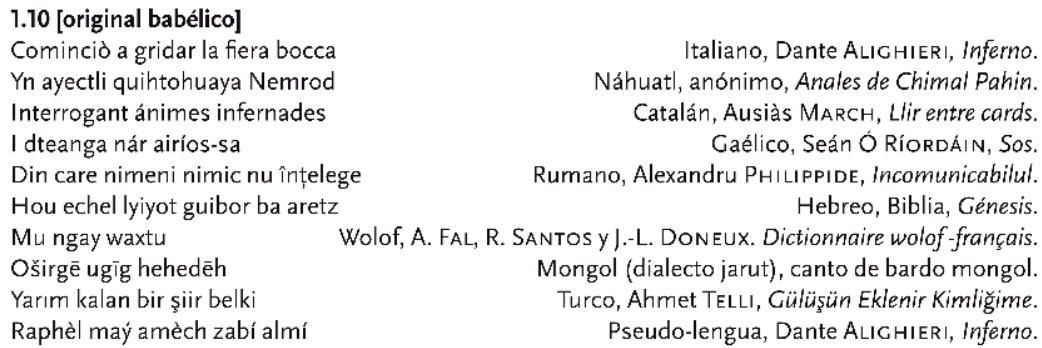

Italiano, Dante AlichierI, Inferno. Náhuatl, anónimo, Anales de Chimal Pahin. Catalán, Ausiàs MARCH, Lir entre cards. Gaélico, Seán Ó Ríordáin, Sos. Rumano, Alexandru PHILIPPIDE, incomunicabilut. Hebreo, Biblia, Génesis. Mongol (dialecto jarut), canto de bardo mongol. Turco, Ahmet TELLI, Gülüşün Eklenir Kimliğime. Pseudo-lengua, Dante ALIG HIERI, Inferno.

No se puede afirmar que la lengua babélica sea absolutamente incomprensible, como lo es, según la ficción dantesca, la "lengua privada" de Nemrod. Una hipotética persona culta, hispanohablante pero no políglota, podría realizar sin mayores esfuerzos la simple lectura continua en castellano del Epígrafe y de la Estrofa Cero, continuando luego por las estrofas del Primer Ciclo. Encontraría muy probablemente dificultades, pero no serían mayores que las que plantean otros poemas culturalistas de nuestra época. Ahora bien 
(siendo capaz, por definición, de descifrar los caracteres romanos), si la misma persona consintiese en leer únicamente el texto babélico, no entendería casi nada. No obstante, encontraría por lo menos un verso inteligible, el de Borges: $Y$ toda la discordia de Babel. Y hasta podría adivinar quizás el italiano de Dante, el catalán de Ausiàs March, o el francés de Víctor Hugo.

Entre esos dos extremos, el análisis de los modos de lectura de la lengua babélica plantea paradojas y aporías.

\section{Aporías de la lectura del Almiraphel}

El collage textual siempre fue posible desde que un escritor tenía una pequeña biblioteca de manuscritos a su disposición, o incluso algunos fragmentos de poemas y cuentos memorizados al escuchar ancianos, cuentistas o griots, pero en el mejor caso, la selección se limitaba a unos pocos géneros en un puñado de lenguas, exigía un trabajo enorme y un largo aprendizaje; ahora todo o casi todo "está en Internet", al alcance de unos clics, con facilidades de traducción semántica cada vez mayores. Como los supermercados de los países ricos ofrecen fruta y verdura fresca de los cinco continentes, el sistema centón del Almiraphel se abastece en citas del mundo entero, de todas las épocas y de todos los géneros. En este sentido, lo que restituye podría verse como unos retazos de trotamundos intelectual, una exhibición de diletantismo, un botín de pillaje colonial.

Sin embargo, todos estos fragmentos reunidos en el mosaico-poema convergen para decir lo mismo, se trata de una universalidad antropológica, como hay universales lingüísticos: no puedo hablar sin hablar del habla, y en mi mundo, como en los mundos de todos, lo único que puedo comunicar es mi incomunicabilidad (Pérez Carrasco 2014: 3), que cualquier otro reconocerá, acercándonos a través de esta fatalidad compartida.

\section{La lectura como traducción}

Ninguna nota o referencia o traducción puede suplir esta aporía. Entonces, el poema como tal la transfiere al nivel de su materialización oral/auditiva (vocear y oír). Y eso vale para cada locutor individual: es la imposibilidad de entenderse que es la condena de Nemrod. Incluso en las traducciones, como no se pueden traducir los versos sin sentido, en seudo-idiomas, tampoco se sabe cómo se han o se pueden pronunciar: ¿Quién habla, en el texto, por lo demás florentino, de Dante? ¿Es Alighieri, o un Nemrod mítico? O bien ¿no importa? ¿se puede pronunciar un no-idioma como un idioma real cualquiera? Cualquier pronunciación del Almiraphel... será por lo tanto incorrecta, una impertinente simulación, una falsificación de lo indecible.

De esta manera, nos acercamos más a la escena (dramática) del poema. A pesar del gran número efectivo y de la infinidad potencial de locutores -explicitados en las notasque se encuentran en el origen de los versos, el locutor primordial nombrado y evocado, Nemrod, incapaz tanto de expresarse como de entenderse, queda en el centro de esta escena, como en "Prosopopeïa" (su boca y sus oídos lo transforman,/(...) en un lugar adonde las palabras /se pronuncian y escuchan ellas solas). Y todo lo cómico alrededor suyo, la cacofonía de lenguajes reducidos a gritos y ruidos, todo lo desordenado y mezclado del babelismo y de la mezcla satírica menipea, el ridículo del 
hablar de los locos, de los cuervos, de las ranas o del trueno, no consiguen atenuar la condición trágica de Nemrod, muy similar a la de Prometeo o a la de Sísifo.

Nemrod, ha desafiado al autor único, único enunciador de la palabra creadora, como Prometeo rompió el monopolio divino del fuego y Sísifo se burló de Zeus y de su brazo fatal más de una vez.

41 Sería demasiado fácil identificar a Nemrod solamente con el creador literario postmoderno cercado por una sobreabundancia de materiales, de medios expresivos y miméticos, de lenguas y maneras de pensar propias a cada una, un creador asediado y a veces sumergido por la interpretación inacabable... Pero aparte de ilustrar la bendición de los profusos saberes, de la extensión de la biblioteca mundial, el Almiraphèl nos enfrenta, en contrapartida, con algo más cruel y más productivo que la "muerte del autor" proclamada por Foucault y Barthes: la tragedia de Nemrod carece de catarsis, y en consecuencia su condena -que el poeta postmoderno intenta transformar en bendición - consiste en una desposesión radical de la autoría personal, combinada con una obligación perpetua a dar voz a las voces de incontables otros, una compulsiva ventriloquia global.

Existiendo solamente en estado de traducción necesaria, inevitable y, al mismo tiempo, imposible, el Almiraphèl se caracteriza simultáneamente por la constancia de su principio (en ambos sentidos de la palabra) y por la variabilidad de sus inacabables realizaciones concretas.

La traducción (semántica) es obligatoria. En primer lugar, porque el poema no aspira en modo alguno a eliminar el sentido, o el horizonte del sentido; los experimentos de desemantisación textual, como los de Isidore Isou, siempre fracasan, dado que el acto mismo de leer implica estar a la expectativa de un sentido; quien lee, si no encuentra sentido en el texto, lo inventa, como ante las planchas de un test de Rorschach. En segundo lugar, porque la composición del centón resulta de una selección (necesaria) de materiales obtenidos por otros tantos actos de traducción. Pero la traducción queda también incompleta y hasta es imposible porque:

1) ninguna traducción puede agotar el potencial semántico de ningún enunciado en ningún idioma -especialmente cuando se lo recontextualiza sin cesar;

2) el significante gráfico y, a fortiori, el significante fónico, no se pueden trasladar tales y cuales a otro contexto sin perder sus efectos estéticos (en el sentido de sensación, aesthesis), y tampoco se podrían encontrar equivalentes satisfactorios - lo que, en la música, permite una transposición instrumental o una orquestación- porque diversos valores semánticos connotativos y potencialmente denotativos siempre quedan adheridos al signo sonoro en la lengua;

3) los no-enunciados, los versos sin sentido, son vitales para la estructura del poema, pero, careciendo de idioma de referencia, ni siquiera pueden traducirse intralingüísticamente.

48 La condición del poema (como se dice condición humana, pero también como se dice condición social y condición de posibilidad) es paradójica en muchos aspectos, tales como la aparente desproporción entre la compleja minuciosidad de la elaboración y la nítida simplicidad del propósito, o lo burlesco (por lo monstruoso o por lo incongruente) de muchos versos frente a la figura de un Nemrod luciferino, primo del Satán del Paraíso perdido miltoniano, puede rozar el absurdo pero nunca se complace en él. 

dadaístas o surrealistas. Hay una contradicción entre el uso sistemático y la exigencia de la traducción, por una parte y, por la otra, las trabas puestas a la traducción y a la interpretación semántica puntual. Todo ello podría crear confusiones, y podría despistar al más dedicado lector, pero no es así. Si por un momento cambiamos el enfoque crítico, reorientándolo del estudio de la fábrica del poema a su tejido, a lo que entretejen su materialidad y su sentido explícito - sin reducirlo nunca a una propuesta monosémica-, nos daremos cuenta de la actualidad antropológica y filosófica del Almiraphèl, muy comparable a principios del siglo 21 a la del Coup de dés pocos años antes de la abstracción pictórica, del cubismo, de la relatividad.

\section{Lectores babélicos}

Empecemos por la cuestión de los lectores virtuales (modelizados por los textos), engendrados, a diferencia de los autores heterónimos, sin mediación del autor empírico. Un lector virtual ${ }^{5}$ es una colección de competencias, deseos y proyecciones definida por un texto, sin intervención ulterior de la crítica, la cual se limita a describir dicha colección de capacidades y limitaciones, agregadas alrededor de rasgos textuales en un espacio de recepción determinado. Por lo tanto, dentro del sistema Almiraphèl, hay que distinguir entre las versiones babélicas y las versiones (casi) monolingües, y luego entre ambas clases con o sin referencias de las fuentes de cada verso del centón:

51 1) El lector virtual del texto babélico a secas (sin traducción ni referencias) será un amador lúdico a la vez de enigmas y de sinsentido, a la manera de quienes aprecian las creaciones aleatorias o letristas;

2) El lector virtual del texto babélico (sin traducción continua pero con referencias), será alguien dispuesto a abrirse a muchas culturas, a disfrutar de la cultura enciclopédica del productor del texto, pero que permanecerá relativamente (aunque no totalmente) indiferente al sentido de cada fragmento, satisfecho con los efectos sensibles e incluso emocionales de la yuxtaposición de idiomas;

3) El lector virtual de una de sus versiones normalizadas (las traducciones a una lengua natural, sobre todo si es la suya materna: castellano, francés, inglés...), acompañada de la lectura de las notas y del texto babélico original, será alguien especialmente interesado por la emergencia de un sentido preciso a partir del sinsentido, y también por la comunidad y universalidad del pensamiento humano, así como por las reglas (constricciones) generadoras del poema, etc.

54 4) El lector virtual de una traducción sin ningún aparato explicativo o referencial se acercará mucho más al modo ordinario de la lectura poética, lírica. Este lector lírico insistirá pues en la armonía, la unidad y coherencia lingüística y semántica, puestas de relieve más que amenazadas por la intercalación de fragmentos asemánticos en nolenguas (como el famoso verso generador y leitmotiv del poema).

\section{Los desdoblamientos del autor}

Como hemos visto, una pluralidad de lectores virtuales surge de las hibridaciones formales constitutivas de la lengua y del poema babélicos.

Cuadernos LIRICO, 21 | 2020 
56 Ahora bien, si uno decide jugar en serio el juego de la ficción, algunas de esas hibridaciones (entre las cuales la multitud de autores reales de cada línea-cita), causan necesariamente la creación de un autor virtual, ficticio (un "gran políglota"), con capacidades muy superiores a la del autor empírico. Schiavetta ha creado no uno sino varios autores imaginarios, heterónimos o "apócrifos".

Schiavetta ha explicado los efectos generativos de sus diversos procedimientos en un artículo publicado en 2016, titulado Comment j'ai trouvé les auteurs de mes textes. Allí describe de qué manera lo que era un evocación temática relativamente simple a partir de un diagramatismo circular, con forma definida, se convierte en un muy complejo proceso de ficcionalización a partir de los diagramatismos híbridos que se desarrollan a partir de lo radicalmente informe, el sinsentido absoluto (ficticio) de Raphél maý améch zabí almí. En efecto, una asemanticidad vocal absoluta, un lenguaje absolutamente privado es una imposibilidad. Postularlo como cierto, como lo hace Dante, es una ficción extrema, un hecho fantástico, un milagro: la posibilidad de una imposibilidad.

Por lo tanto, en toda lógica, según la fórmula acuñada por Jan Baetens, escribir el Almiraphel, realizar "la generación de sentido a partir del sinsentido" (Baetens 2002: 121) sólo puede ser una ficción, una proliferación de ficciones.

En las diez páginas liminares de Jugar en serio, el prefacio de Antes de los apócrifos (2018), la historia imaginaria del Almiraphèl se llama «la novela de Carmen y Bruno» y contiene comentarios como éste: los autores-personajes nacieron de los poemas, no los poemas de los personajes. De ese hecho proviene el título, a primera vista enigmático, de esta antología (Schiavetta 2018: 8).

El título del poema, de los textos en prosa narrativa o ensayística que lo acompañan y hasta los nombres mismos de sus «autores» han ido cambiando con el tiempo. Para evitar confusiones hemos preferido designar a los muy cambiantes personajes-autores «apócrifos», ${ }^{6}$ como «la heterónima» y «el heterónimo». Por la misma razón, la claridad, ha sido siempre importante distinguir entre las fechas imaginarias del mundo de la ficción y las fechas efectivas de la escritura y de las reescrituras de los textos generados por el verso de Dante.

\section{El heterónimo}

61 El heterónimo (llamado Gianfranco en 2005) comienza a escribir su obra en Zurich, poco después de haber asistido al espectáculo durante el cual Hugo Ball interpretó sus poemas asemánticos en el Cabaret Voltaire (Zurich, 23 de junio de 1916):

Durante las vacaciones escolares del año 1916, Gianfranco acudió asiduamente al Cabaret Voltaire en compañía de su primo Elvio Zagghi (1898-1997), quien exponía allí un cuadro-poema cubo-futurista. Gianfranco, por su parte, experimentó una auténtica conmoción ante los sonidos incomprensibles proferidos por Hugo Ball, mientras éste interpretaba solemnemente Elephantenkarawane, uno de esos poemas abstractos dadaístas que rivalizaban por entonces con las onomatopeyas y las parole in libertà de los amigos de Marinetti. Las conversaciones que tuvo luego con Ball ejercieron una influencia determinante sobre el muy joven Gianfranco, quien habría de adherir durante varios años a las ideas de Dadá.

62 En el mundo novelesco del ensayo-ficción publicado en Hablar de poesía, dos fechas ficticias encuadran la historia imaginaria el poema babélico: la "última versión", titulada Almiraphèl (fecha ficticia: 1978) y la versión princeps, dadaísta, titulada RAPHÈL 
(fecha ficticia: 1916). ¿De dónde vienen las razones de ese desplazamiento hacia el pasado de la historia real de la escritura de poema babélico, que comienza en 1983 y que continúa hasta la actualidad? La respuesta es categórica: a causa de Dante... Raphél maý améch zabí almí.

El verso de Nemrod, en razón de su papel narrativo en la Comedia, como ejemplo de frase sin ningún sentido para quien la escucha, no es del todo ajeno a los poemas dadaístas de Hugo Ball, poemas sin ningún sentido para sus auditores, tanto de entonces como de hoy. En el desarrollo ficcionalizante de la escritura diagramática, esa asociación de ideas genera el tema del asemantismo poético y determina con exactitud una localización geográfica (Zurich) y una fecha (el 23 de junio de 1916), circunstancias de la performance dadaísta de Ball. A su vez, ese evento central determina ciertos datos posteriores (ficticios) más complejos. Así comienza a tomar forma la «biografía» del heterónimo: su frecuentación del Cabaret Voltaire, su participación al movimiento de Tzara y luego al de Breton, su ruptura con este último y la consecutiva fundación de la revista suiza Ánima, bastión del "surrealismo disidente" de Gianfranco y de sus amigos, todos ellos fervientes discípulos del zuriqués Carl Gustav Jung [estos elementos figuran en el ensayo ficción de 2005].

Es también evidente que el verso de Nemrod ha evocado la memoria de la confusión babélica y por consiguiente el tema del plurilingüismo, tema que fue sin duda el factor desencadenante de la invención de la autoría apócrifa; en todo caso, es lo que Schiavetta mismo ha declarado:

Teóricamente, un políglota casi sobrehumano podría leer ese centón de corrido, mas en realidad el poema no puede ser descifrado por entero, a menos de utilizar una traducción. Meditar sobre ese detalle dio nacimiento, para mi sorpresa, a uno de esos seres ficticios que Pessoa ha llamado heterónimos y Machado apócrifos: un gran políglota capaz no sólo de leer, sino de escribir el poema babélico directamente en 70 lenguas (...) un yo distinto de mi yo, un nuevo poeta dotado de una personalidad compleja y fuerte, de una rica biografía y de nuevas obras apócrifas. De este modo, Almiraphel, en el cual la historia imaginaria de la composición del poema babélico y el poema propiamente dicho se mezclan en una ficción novelesca, se aparenta por ciertos aspectos a Monsieur Teste o a Juan de Mairena y por otros a Pálido fuego de Nabokov (Coste y Schiavetta 2012 : 9).

En las etapas evolucionadas de la ficcionalización, donde se sobredeterminaron los elementos suizos precedentes, el tema del plurilingüismo ha contribuido de manera capital a forjar otros aspectos de la personalidad del heterónimo. Él conoce desde su infancia las grandes lenguas europeas de cultura, sencillamente porque el trilingüismo alemán-francés-italiano no es infrecuente en Suiza. Por otra parte, en 1916, el heterónimo está cursando en la Universidad filología y paleografía, y por esa razón ha iniciado estudios de egipcio antiguo, copto, arameo, hebreo, akádico, sumerio, etc. Y es normal que Gianfranco ya domine el griego y el latín, aprendidos en el Gymnasium. En consecuencia, es perfectamente verosímil que el heterónimo sea un "gran políglota".

Conviene decir algunas palabras sobre la versión princeps (ficticia) del poema babélico: el RAPHEL de 1916 cuyo título en mayúsculas es un pastiche de la tipografía cubofuturista de la época. En el ensayo-ficción RAPHEL es un collage de unos veinte versos que se transformará más tarde en los diez versos de la "Estrofa Cero" (copiada más arriba). Salvo el verso en italiano Cominciò a gridar la fiera bocca, ninguna de las otras citas antiguas tiene un sentido conocido en sus fuentes textuales, todas auténticas.

Posteriormente, entre las entrelíneas incomprensibles del RAPHÈL de 2019, el heterónimo irá introduciendo versos políglotas hasta llegar a producir el último 
Almiraphel ficticiamente fechado en 1978, y ficticiamente traducido al castellano por la heterónima. Este personaje femenino aparece en la versión de Hablar de poesía solamente como una gran políglota (Irma) que traduce al castellano la obra babélica que el heterónimo había enviado a otros grandes políglotas:

Durante más años todavía, por intermitencias, y a partir de la lista de todos esos versos "encontrados", [el heterónimo] fue armando, como quien arma un rompecabezas, incontables variaciones combinatorias de su poema. Finalmente, ya más que nonagenario, decidió que una enésima versión de Almiraphel podía ser la definitiva, y la envió a algunas y algunos de los que habían sido sus alumnos, porque los sabía capaces de leer directamente la mayor parte del texto original babélico. Tomó la precaución de anexar, a los envíos particulares, una traducción palabra por palabra de los versos escritos en aquellos idiomas que cada destinatario ignoraba. Les rogó que fijasen sus lecturas del poema (sus interpretaciones) por medio de traducciones en la lengua materna de cada cual. Sólo media docena de traducciones fueron realizadas enteramente, lo suficiente, sin embargo, para alcanzar el objetivo de [Gianfranco]: la diversidad de las lecturas. (Schiavetta 2005: 44).

\section{La heterónima}

La heterónima, después de 2005 alcanzará una estatura igual o superior a la del heterónimo. Schiavetta ha publicado en 2006 la más extensa versión impresa del ensayo-ficción y del poema babélico: "Aspectos digitales del Almiraphèl/ Aspects numériques de l'Almiraphèl", ya referenciada más arriba. En esa redacción de la historia, el poema babélico, titulado Almiraphèl remake, se ha transformado en un proyecto común de los dos autores imaginarios, proseguido por la heterónima sola (llamada Zelia en esta versión) tras la muerte del heterónimo.

Hoy, a fines del 2019, Carmen y Bruno parecen ser los nombres definitivos de los dos autores apócrifos. 0 por lo menos así deberían figurar ambos en la redacción definitiva del ensayo-ficción transformado en "la novela de Carmen y Bruno", tal como Schiavetta lo ha anunciado en "Jugar en serio" (Schiavetta 2018: 15).

Schiavetta declara : la novela de Carmen y Bruno pertenece al género fantástico. Es, entre otras cosas, una versión irónica del mito de Eurídice y Orfeo, de Helena de Tiro y Simón el Mago, de Margarita y Fausto, etc. (7-17). Subrayemos que el autor, al enumerar esas parejas célebres, nombra los personajes femeninos antes que los masculinos. Ese detalle nos hizo pensar que la heterónima heroína o anti-heroína llamada Carmen, aunque aparece como co-autora en la historia imaginaria del poema babélico, no aparece de ninguna manera explícita en el Almiraphel propiamente dicho.

En cambio, en "Jugar en serio" se atribuyen a "Carmen" numerosos poemas anteriormente publicados por Schiavetta:

Algunos poemas de Carmen, donde aparece de manera todavía inmadura su estilo propio, fueron publicados bajo mi nombre en mi último libro de poemas, Con mudo acento (1995). [...] Carmen siempre estuvo segura de haber sido en su vida anterior una dama española del siglo diecisiete, la que habla en "Respuesta de la Dama a don Francisco de Quevedo", así como en varios [otros] poemas como "Ronda de los mortales", "Conjunción de opuestos", "Fénices", "La ninfa en la Estigia", "Las bodas de Eco", "Madonna Intelligenza parla", "Página entregada al fuego", "Espejo de los comediantes" o "Sextina caótica” (Schiavetta 2018: 15).

Podríamos quizás comprender mejor el enigma de la heterónima, analizando los poemas que Schiavetta le atribuye explícitamente. Pero este artículo es ya demasiado 
largo para que nos sea posible hacerlo. Baste con comprobar que en la "Sextina caótica", Carmen escribe anagramáticamente una frase digna de la Lengua de Adán, (lengua que dice lo que hace y hace lo que dice): Del caos saco asco, ocas, caso y cosa, verso que aparece en el terceto inicial y final de esa sextina. Nos parece que es nuestro deber, antes de transcribir esos tres versos, dar enteramente razón a Martine Marzloff cuando ella afirma que la escritura de Schiavetta busca superar a sus antiguos modelos "sin tomarse demasiado en serio".

Del caos saco asco, ocas, caso y cosa

porque el Caso fortuito es ley del caos

y porque quedan ocas en el saco.

\section{BIBLIOGRAPHY}

Baetens, Jan, “Écriture digitale et poésie: Raphèl de Bernardo Schiavetta”, Lendemains n 127, 2002, p. 121-131.

Baetens, Jan, y Schiavetta, Bernardo, "Définir la contrainte", Baetens y Schiavetta (ed.), Le Goût de la Forme, París, Noésis, 2004, p. 344-347.

Bénabou, Marcel., "De la regla a la constricción, el Oulipo", Antonio Altarriba Ordoñez (ed.), Sobre literatura potencial, Encuentro sobre Literatura Potencial, Álava, Universidad Del País Vasco,1987, p. 7-12.

Charles, Michel, Rhétorique de la lecture, Paris, Seuil, 1977.

Coste, Didier, “Trois conceptions du lecteur”, Poétique no 43, 1980, p. 354-371.

Coste, Didier y Schiavetta, Bernardo, Texto de Penélope, diálogos con Didier Coste, París, Reflet de Lettres, 2012. [1999]

Dante, Alighieri, Divina Commedia, Giuseppe Vandelli (ed.), Milán, Hoepli, 1989.

Eco, Umberto, Lector in Fabula, Barcelona, Lumen, 1993, [1979]. Traducción de Ricardo Pochtar, Fonsalido, María Elena, "Soneto, especularidad, tradiciones. Una lectura de Fórmulas para Cratilo de Bernardo Schiavetta", El jardín de los poetas. Revista de teoría y crítica de poesía latinoamericana, Año II, $n^{\circ} 2$, primer semestre 2016, p. 41-54.

Iser, Wolfgang, The Implied Reader, Baltimore, Johns Hopkins University Press, 1978

Lope de Vega, Obras poéticas de Lope de Vega, José Manuel Blecua (ed.), Barcelona, Planeta, 1969.

Marzloff, Martine, "De l'échantillon comme modèle poétique dans l'oeuvre de Bernardo Schiavetta", Corinne Bayle y Eric Dayre (ed.), Poète cherche modèle, Rennes, Presses Universitaires de Rennes, 2017.

Mesa Gancedo, Daniel, “El lugar y la fórmula: 'Cubo de Kepler' de Bernardo Schiavetta, un laberinto poético contemporáneo", Tropelías. Revista de teoría de la literatura y literatura comparada N¹5-17, 2004-2006, p. 395-410.

Monk, Ian, "Raphèl, une traduction anglaise", Jan Baetens y Bernardo Schiavetta (ed.) Le Goût de la Forme, París, Noésis, 2004, p. 334-339. 
Pérez Carrasco, Mariano, "Dante y Nembrod en la Babel de las lenguas poéticas contemporáneas", Web. Consultado el 18 de diciembre 2019.

Perloff, Marjorie, Radical Artifice: Writing Poetry in the Age of Media, Chicago, University of Chicago Press, 1991, p. 139;

Poier-Bernhard, Astrid, "Babylonische Kombination als literarisches Verfahren; "o du roher iasmin" von Oskar Pastior und "Raphèl" von Bernardo Schiavetta im Kontext oulipotischer Poetologie ", Krise und Kritik der Sprache zwischen Spätmoderne und Postmoderne, Reindhard Kacianka y Peter Zima (ed.), Tubingen \& Basel, Verlag, 2004, p. 195-211.

Schiavetta, Bernardo, Diálogo, Prometeo, Valencia, 1983.

---, Fórmulas para Cratilo, Visor, Madrid, 1990.

---, "Poemas diagramáticos", Texturas : Nuevas Dimensiones del Texto y de la Imagen n², 1991-92, p. 44-45.

---, "Motivation de la métrique et diagrammatismes", en Cahiers de poétique comparée de l'INALCO $n^{\circ} 20,1992$, p. 95-117.

---, “Hiperglosas”, Serna, Angela y Varela, Julio (ed.), La escritura creativa, Vitoria, Arteragin, 1997, p. 77-88.

---, "Raphèl”, Jean-Pierre Balpe y Sylvie Leleu-Merviel (ed.), Hypertextes, hypermédias, nouvelles écritures, nouveaux langages, Paris, Hermes-Lavoisier, 2001a, p. 223-237.

---, “Raphèl, poème babélique illimité”, Document numérique, Vol. 5, 2001b, p. 17-31

--- , Autres hétéronymes, Poésie n 91, febrero 2002, p. 40-60.

---, “Raphèl", en Éc/arts \# 3, 2003, p. 374-375.

---, “Fragmentos de un poema babélico", Hablar de Poesía n 14, 2005, p. 40-50.

---, “Aspects numériques de l'Almiraphèl”, Formules no10, 2006a, p. 213-259.

---, “Almiraphel Remake”, Formules nº 10, 2006b, p. 237-259.

---, “Comment j'ai trouvé les auteurs de mes textes», Formules nº 20, 2016, p. 253-279.

---, "Jugar en serio" [prefacio], Antes de los apócrifos, Buenos Aires, Audisea, 2018, p. 7-17.

---, Antes de los apócrifos, Buenos Aires, Audisea, 2018.

\section{NOTES}

1. El autor de estas páginas agradece a Bernardo Schiavetta y a Susana Romano Sued los intercambios epistolares que han permitido esclarecer muchos pormenores de la compleja historia de esta lengua babélica.

2. Técnica conocida en la Antigüedad bajo dos nombres, kento en griego y cento en latín; ambos significan patchwork.

3. Para mayores detalles, ver la bibliografía final.

4. Raphél maý améch zabí almí es un endecasílabo con final agudo, que tiene un ritmo yámbico pleno (todas las sílabas pares están acentuadas). Según la hipótesis de la edición Vandelli de la Divina Comedia, esa (y no otra) es la grafía de los más antiguos manuscritos; estos siguen fielmente un regla del latín medieval: la de acentuar agudamente todas las palabras extranjeras. El verso de Nemrod sería así (muy significativamente) el único verso disonante de la Divina Comedia: 
rima tan sólo visualmente en "almi» pero no es una rima propiamente dicha. En el Almiraphel jamás aparecen las variantes "amecche" o "izabi", las cuales intentan transformar en endecasílabo llano este verso con final agudo.

5. Ver Michel Charles, Rhétorique de la lecture, Paris, Seuil, 1977; Wolfgang Iser, The Implied Reader, Baltimore, Johns Hopkins University Press, 1978. Umberto Eco, Lector in Fabula, [1979], trad. española, Barcelona, Lumen, 3a edición 1993. Didier Coste: "Trois conceptions du lecteur", Poétique, no 43, 1980, p. 354-371. Michel Charles decía que el lector es un rol (papel) y nada más; Iser contrasta el "lector implícito" con el lector efectivo; Eco define un "lector modelo" como un papel desempeñado por un conjunto de competencias para actualizar el sentido de un texto. Yo sigo prefiriendo la expresión "lector virtual" como un potencial de actividad no solamente interpretativa. Además, la mayoría de las teorías de la lectura literaria se limitan a ejemplos narrativos en los cuales los personajes interfieren con la construcción del lector virtual. La lírica no alienta la identificación con seres imaginarios, sino una experiencia más autónoma del mundo textual.

6. Carmen y Bruno, pero también Zélia Zagghi, y sus hijos Zag-\&-Zig@, artistas contemporáneos, Delia Carnicer i Borda, Irma Maza, Selvio Zagghi, Angelo della Schiavetta, Gianfranco Gonzalvi, etc., etc. Ver Marzloff (2017)

\section{ABSTRACTS}

From 2001 onwards Schiavetta has published different printed and online versions of his work in progress, a multilingual text on Babel, Almiraphel. It is a patchwork or cento of quotations in more than sixty languages, a piece of procedural poetry which rewrites a previous poem of the author, namely "Prosopopeïa", a poetical commentary (the Spanish poetic form named "glosa") on a verse of the Divine Comedy (Inferno, XXXI, 67) written by Dante in the imaginary language of the giant Nimrod, the builder of the Tower of Babel. Nimrod's punishment is an eternal lack of comprehension: he can neither understand nor be understood. Schiavetta's imaginary babelian language is a collage of over a hundred quotations pieced together by a great polyglot, an imaginary author (heteronym). This essay addresses the process involved in the writing of the poem Almiraphel.

Desde 2001 Schiavetta publica regularmente versiones del Almiraphel, un work in progress que habla babélicamente de Babel; la obra es una larga versión multilingüe (en más de 60 idiomas) de su antiguo poema "Prosopopeïa". Como éste último, el Almiraphel es la glosa de un verso del Inferno (XXXI, 67) en el cual Dante inventa una frase sin sentido pronunciada por el constructor de la Torre de Babel, el gigante Nemrod, condenado a hablar un idioma (ficticio) que nadie puede comprender. La lengua babélica imaginaria de Schiavetta es un collage de más de cien citas rigurosamente referenciadas, collage realizado por un hetéronimo gran políglota (el autor ideal del poema). Este artículo interroga los diferentes procedimientos de composición del Almiraphel.

Schiavetta publie régulièrement, depuis 2001, de nouvelles versions de l'Almiraphel, un work in progress qui parle babéliennement de Babel. L'œuvre est une longue version multilingue (en plus de 60 langues) de son ancien poème "Prosopopeïa". À l'instar de ce dernier, l'Almiraphel est la glose (forme fixe poétique, la "glosa española ») d'un vers de l'Enfer (XXXI, 67) qui, selon Dante, ne peut avoir aucun sens pour nous. Elle est prononcée par le constructeur de la Tour de Babel, le 
géant Nemrod, condamné à parler une langue (imaginaire) que personne ne peut comprendre. La langue babélienne imaginaire de Schiavetta est un collage de plus de cent citations rigoureusement référencées, collage réalisé par un hétéronyme grand polyglotte (l'auteur idéal du poème). Cet article interroge les différents procédés de composition de l'Almiraphel.

\section{INDEX}

Mots-clés: autotélisme, autoreprésentation textuelle, métatextualité, contrainte littéraire, poésie expérimentale

Palabras claves: autotelismo, autorepresentación textual, metatextualidad, procedimientos literarios, poesía experimental

Keywords: autotelism, metatextual representation, literary constrain, procedural poetics, experimental poetry

\section{AUTHOR}

\section{DIDIER COSTE}

Université Bordeaux Montaigne

didier.coste@gmail.com 